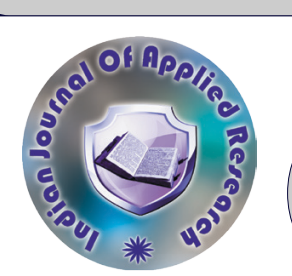

Healthcare

\title{
A STUDY OF IMPACT OF EXCESSIVE USE OF MOBILE PHONES ON EYE DURING COVID-19 PANDEMIC
}

Kshama Pandey*

Optometry Scholor, Department Of Optometry Uttar Pradesh University Of Medical

Science *Corresponding Author

Aditya Tripathi

Lecturer, Uttar Pradesh University Of Medical Science

ABSTRACT Purpose: This study was designed to determine the impact of increased screen time during covid-19 pandemic for online classes.

Methodology : A cross sectional survey on 200 students from different schools and colleges was designed to find changes in eye condition due to increased screen time using a validate questionaire.

Result: A comparison of statistical analysis on 200 students reveals that near about $70 \%$ students are dependent on mobile phone for online classes whereas $30 \%$ students use other electronic gadgets. The screen time of students have been increased 4 times in this pandemic due to which students experiences asthenopic symptoms.

Conclusion: The increased screen timing tends to appearance of asthenopic symptoms and eye strain in maximum students along with decrease in concentration. It suggest that before conducting online class students should be trained about the right way of taking online classes so that it's adverse effects can be reduced.

KEYWORDS : Eyestrain, covid -19 pandemic, online education, asthenopic symptoms , questionaire

\section{INTRODUCTION :}

The entire world is dealing with the global pandemic of coronavirus in their own ways. From self isolation to government imposed lockdown to minimise the spread of safety of its people.Due to this pandemic schools and colleges are closed keeping the children out of school and college. Education has taken a new platform which is known as online education which leads to excessive increase in screen time.students are now attending online classes and completing assignments online which thus increase their daily screen time. This leads to the appearance of the asthenopic symptoms in the students. Asthenopia is an eye condition that manifest through non- specific symptoms such as fatigue, pain in or around the eyes . blurred vision, headache, and occasional double vision symptoms often occur after long term use of computers, digital devices, reading, driving long distances or other activities that involve extended visual tasks. When concentrating on a visually intense task, such as continuously focussing on a book or electronic gadget monitor the Ciliary muscles and the extraocular muscles are strained. This causes discomfort, soreness or pain on the eyeballs. Asthenopic symptoms includes - watering eyes, Dry eyes, Blurred vision, sensitivity to light, headache, Neck and shoulder pain, difficulty in concentration, burning of eyes, and itching of eyes Objective of the study is to determine the impact of increased screen time during covid-19 pandemic for online classes on the students and to aware the students about right way of taking online classes .

\section{METHODOLOGY:}

The survey was conducted in three months (April to June) in different schools and colleges in the eastern Uttar Pradesh. A structural questionaire was designed based on the experiences of the Mobile users and related to the asthenopic symptoms. This questionaire was taken to evaluate the asthenopic symptoms experienced by the students due to increased screen time. This survey was done on 200 students from different schools and colleges to find changes in eye condition due to increased screen timing. During evaluation following common questions were asked to the subjects:

1. How much time you spend for online class??

2. Device used for online class?

3. Usage of mobile other than online class?

4. Total usage of digital screen including online class and other online works?

5. Common symptoms appeared after long hour's online class?

The data was analyzed with the help of the SPSS 21 version.

After getting responses from 200 students, it was observed that 161 students were facing asthenopic symptoms at the end of the day. These students were advised ${ }^{2}$ some key points to follow to prevent from these symptoms appeared after long screen hours through e - mail provided by them. The key points include:

1. Take a frequent break of every 1 hour and do some stretching of the body for a movement. Make sure that after online sessions they spend minimum time with devices.

2. Sit on a chair with table with proper posture .Try to avoid sitting with improper posture. The back should be straight, arm in rest and adjust the height of the desk or chair so the eyes should be slightly above screen.

3. Make atleast $50-70 \mathrm{~cm}$ distance from your digital screen like tablets, phones or laptops.

4. Do eye muscles exercise

\section{RESULT:}

It was found that out of $200(\mathrm{n}=200)($ mean age $=17.5 \pm 4.5) 34(17 \%)$ were school going while $166(83 \%)$ were college Students .Out of them $140(70 \%)$ uses mobile phones , $22(11 \%)$ uses laptop while $38(19 \%)$ uses both for their online classes. Total mean usage of mobile phones up to 6 hours is $144(72 \%)$ while more than 6 hours usage is by $56(28 \%)$ subjects. Due to increased screen timing the students experiences asthenopic symptoms. Out of total $176(88 \%)$ subjects reported headache and tiredness, $114(57 \%)$ subject reported poor concentration; sleepiness and irritability.172 (86\%) subjects complained fatigue in or around the eyes whereas $53(26.50 \%)$ subjects dry eyes. The complaint of blur vision was reported by $59(29.50 \%)$ subjects. About 94(47\%) reported difficulty in concentration and watering from their eyes. Based on this data dry eyes $(26.50 \%)$ and blur vision $\left(29.50 \%\right.$ ) were least commonly experienced symptoms ${ }^{3}$.

Symptoms (Headache, tiredness, poor concentration, sleepiness, irritability, and fatigue) was statistically significant at the level of $\mathrm{p}=$ 0.77 at the cause of asthenopic symptoms.

\section{DISCUSSION:}

Now -a- day's life style obliged the whole world to shift to the modern technology where the digital screens are the master piece of the life process. The emergences of handheld and portable digital screen have multiplied the number of devices used by human kind hundreds of times.

In the last 5 months the use of digital screen has increased multiple times for online education and therefore students are consuming their most of the time on smart phone and digital screen.

Graph 1.1 shows that out of total respondents $17 \%$ were school going while $83 \%$ were college going students.

Graph 1.2 reveals that the duration of online classes varies for all respondents $20 \%$ of total respondents attain more than 6 hours of online class, whereas $50 \%$ students spend 4 - 6 hours for online classes. About $37.2 \%$ students attain $0-2$ hours whereas $35.4 \%$ students attain $2-4$ hours

Graph 1.3 shows that after taking online classes respondents shows asthenopic symptoms. Most common symptoms are headache, poor 
concentration, and fatigue in or around eyes.

$88 \%$ of total respondents reported headache and $86 \%$ reported fatigue in or around eyes.

Poor concentration and sleepiness was reported by $57 \%$ respondents. Dry eyes were reported by $26.50 \%$ respondents.

All these Data were statistically analyzed and extremely significant.

Graph 1.1: Graph showing institution wise distribution of total number of subjects among

\section{Number of students}

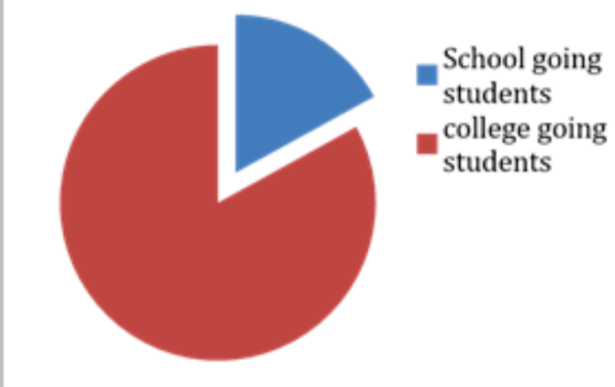

Graph 1.2: Graph indicating total number of hours spent on digital screen for online class.

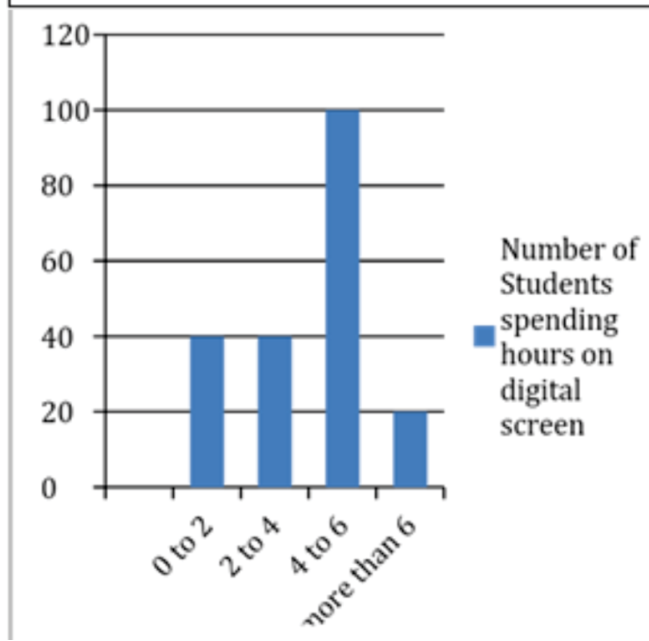

Graph 1.3: Graph showing respondent symptoms after online class

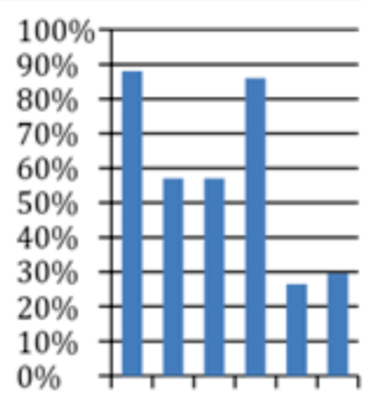

Responden

ts

symptoms

after online

class

\section{ACKNOLEDGEMENT:}

Authors would like to thanks Miss Priti Pandey (M.Sc. Chemistry) who have contributed and assisted greatly till the execution of this article. I would also like to thanks to the subjects who responded seriously and help to bring accurate data for this manuscript.

\section{REFERENCES}

1. Benjamin William (2006) Clinical refraction (2nd edition) Elsevier

https://www.mivision.com.av/2014/08//zeiss-a-new-digital solution/ Andrew LIN, March 12, 2019.

3. Acharya, Jayant P. (2013) A study on some of the common health effects of cell phones amongst college students. Community medicine and health education (3:4) http://dx. doi. org/10.4172/21610711.100214 